\title{
The Effects of Utilizing Telegram App to Enhance Students' ESL Writing Skills
}

\author{
Murni Hayati binti Mohd Dollah: PhD Student, Faculty of Education and Liberal Studies, City University \\ Malaysia.
}

-Subadrah Madhawa Nair: Lecturer, Faculty of Education and Liberal Studies, City University Malaysia.

Walton Wider: Lecturer, Faculty of Business, Communication and Law, INTI International University Malaysia.

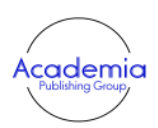

International Journal of Educational Studies

Volume 4, Issue 1, pp. 10-16

DOI: $10.53935 / 2641-533 x . v 4 i 1.55$

Corresponding Author: Subadrah Madhawa

Nair

Email: subadrah.nair@city.edu.my Funding: This study received no specific

financial support.

Article History:

Received: 1 July 2021

Received: I July 2021

Revised. 3 August 2021

Published: 9 Septemt 2021

(C) 2021 by the authors; licensee Academic Publishing Group
ABSTRACT: Mobile learning provides students to learn anywhere without the need of physical classroom. The main objective of this study is to investigate whether the utilization of Telegram app can enhance students' ESL writing skills. The second objective is to investigate whether the utilization of Telegram app can enhance students' perceptions towards ESL writing skills. Quasi-experimental one group pre-test post-test design was employed in this study. The students from the experimental group were given a pre-test (descriptive writing test) via Telegram app and their essays were marked by their teacher. The experiment lasted four weeks, and students were taught ESL writing skills using the Telegram app during that time. After the intervention a post-test was administered. This study used two types of instruments, pre-test, post-tests and a questionnaire. The data from the pre-test and post-test were analyzed using the paired sample t-test, and the questionnaire was analyzed using descriptive statistics. This study shows some interesting findings. Firstly, the results indicate that the utilization of Telegram app enhances students' performance in their overall ESL writing; spelling, punctuation, organization, vocabulary, grammar, content quality and creativity. In addition, students' perceptions towards ESL writing skills enhanced significantly. This study has effective pedagogical implication because utilization of Telegram app helps to improve students' writing skills. Furthermore, the findings suggest that ESL teachers can use Telegram app as an alternative method in teaching writing skills.

Key words: Telegram app, writing skills, Essay writing, ESL, Mobile learning, Form five pupils, E-learning, Mobile phones, Pedagogical tool, Communication devices.

JEL Classification: I20, Education and Research Institutions: General; I23, Higher Education; Research Institutions.

\section{Introduction}

Nowadays, all schools both in primary and in secondary level need to keep pace with the progress of the evolution of Information and Communication Technologies (ICT) in teaching and learning. When the coronavirus COVID-19 is affecting 213 countries around the world, online learning which is also known as elearning be implemented (Nadikattu, 2020; Soni, 2020). In Malaysian schools, e-learning has been introduced to empower school students who are in different geographical locations to study and do their revision under teachers' supervision (Abbasi \& Hashemi, 2013). The e-learning is not hard to be applied in education system in Malaysia as both the primary and secondary school students can easily access the communications devices such as mobile phones as these are reasonably priced to own (Adams, Sumintono, Mohamed, \& Mohamad Noor, 2018). Adams et al. (2018) realized that one new aspect in student's life nowadays is the emergence and 
spread of utilization of mobile phones in e-learning which be called as mobile learning or M-learning. The comprehensive utilization of mobile phone enables it fundamental for teachers to discover the effect of utilizing this modern trend in education. The introduction of one of the most popular mobile app named Telegram app makes the world becomes small (Aghajani \& Adloo, 2018). It gives everyone the opportunities to be independent learners where there is no more accepting information and receiving knowledge merely from teachers in a conventional way. Teachers are able to get advantage from this innovation in many ways, particularly in the utilization of Telegram app which can be expanded far beyond the classroom. In their studies, Aghajani and Adloo (2018) found that Telegram app is more helpful to the students in terms of flexibility and duration of learning. Besides, it is easy for the students to access the Internet via their smartphones. This empowers them to utilize their wit, erudition, resources and learning skills, which have not been taught in the classroom.

Telegram app also expands rapidly and diversified into a great number of advantages in teaching and learning (Aghajani \& Adloo, 2018). For example, through the utilization of Telegram app, it gives students an opportunity to cooperate with one another or connect with friends in other nations as the Telegram app can have 1,000 members per group and the members can access to old or past messages. Moreover, it can be utilized for technological choices to monotonous classroom lectures by having students to involve in interactive activities and tasks like quizzes, open-ended questions, group projects and contents or materials sharing. Telegram app can also serve with large file transfer and compatible file format like jpg, audio, movie, pdf, Excel, Word and PowerPoint. In light of this, the researcher plans to investigate whether the utilization of Telegram app can enhance students' ESL writing skills as well as their perceptions of ESL writing skills.

\subsection{Research Questions}

RQ1. Is there a significant difference between the pre-test and the post-test (after using the Telegram app) in terms of students' ESL writing skills?

RQ2. Is there significant difference on students' perceptions towards ESL writing before the utilization of Telegram app compared with their perception after the utilization of Telegram app?

RQ3. What are the students' perception on using the Telegram app to improve ESL writing skills?

\section{Review of Literature}

Altogether, 27 reviewed journal articles related with this study were found from 11 countries: China, the Czech Republic, Iran, Japan, Lebanon, Russia, Saudi Arabia, Spain, Sri Lanka, Taiwan and Turkey.

\subsection{Studies on Effectiveness on Using Mobile Learning}

Mobile learning is becoming an important feature in today's education, according to most studies. According to reports, students are becoming more interested in mobile learning (Lin \& $\mathrm{Yu}, 2017$ ). This perspective is agreed by other researchers who also believe that students readily acknowledge the use of communication devices such as mobile phones in learning (Andujar, 2016; Khabsarian-Dehkordi \& AmeriGolestan, 2016; Kuimova, Burleigh, Uzunboylu, \& Bazhenov, 2018; Lin \& Yu, 2017). Hao, Lee, Chen, and Sim (2019) stated that teachers usually use mobile learning as motivation to help low-achieving students to achieve well in study. Jamaldeen, Hewagamage, and Ekanayaka (2018) approved that students were enthusiastic about mobile learning and found it to be beneficial.

Regarding language skills practiced in mobile learning, a number of researches focused their study writing skills (Aghajani \& Adloo, 2018; Awada, 2016), speaking (Hwang, Hsu, \& Hsieh, 2019), vocabulary (Celik \& Yaviz, 2017; Khabsarian-Dehkordi \& Ameri-Golestan, 2016; Klímová \& Pražák, 2019; Lin \& Yu, 2017), listening (Hwang et al., 2019) and reading (Naderi \& Akrami, 2018).

Jin and Yan (2018) stressed that mobile learning can improve students' learning. Some teachers and parents, on the other hand, are still opposed to mobile learning because they are unaware of its benefits. Furthermore, the teacher must devote a significant amount of time to mobile learning preparation.

Similarly, Celik and Yaviz (2017) found that mobile learning is efficient in ESL, but the utilization of it must be guided and controlled by the teachers. Kuimova et al. (2018) noted that mobile learning not only improves students' cognitive activity but also strengthen students' independence in learning. KhabsarianDehkordi and Ameri-Golestan (2016) also concluded that students who used mobile learning was undoubtedly surpass. 


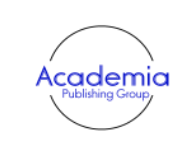

International Journal of Educational Studies

Volume 4, Issue 1, pp. 10-16

2021

DOI: 10.53935/2641-533x.v4i1.55

"Corresponding Author: Subadrah Madhawa

Nair

Email: subadrah.nair@city.edu.my

Funding: This study received no specific

financial support.

financial support.

Article History:

Received: 1 July 2021

Revised: 3 August 2021

Accepted: 23 August 2021

tember 2021

(C) 2021 by the authors; licensee Academic Publishing Group
On the other hand, Leis, Tohei, and Cooke (2015) found that students who are allowed to use their mobile phones in class are more likely to study outside of class. Thus, teachers are advised to allow their students to use cell phones for schoolwork. Darmi and Albion (2014) found that the assimilation of mobile phones in ESL is adequate to students and play a vital aspect in developing language skills. They also confirm that mobile phones are acknowledged by ESL students.

In addition, Abbasi and Hashemi (2013) have studied the effect of utilizing mobile phones on the vocabulary retention among ESL students. The finding determines that the use of mobile phones by ESL students features a significant effect on their vocabulary retention. Ally, McGreal, Schafer, Tin, and Cheung (2007) reviewed some studies that integrated the utilization of mobile learning in teaching English. The results indicated that mobile learning has enhanced students' performance in English language.

\subsection{Studies on the Effectiveness of Learning English via Telegram App}

Several studies showed that the utilization of Telegram app in ESL learning is effective (Heidari-shahreza \& Khodarahmi, 2018; Xodabande, 2017). The utilization of Telegram app in English language learning improves a various aspects of ESL students' English language skills (Aghajani \& Adloo, 2018; Ghobadi \& Taki, 2018; Naderi \& Akrami, 2018; Setiawan \& Wahyuni, 2017; Xodabande, 2017). Zamakhsari (2018) also stressed that utilization of Telegram app enhanced students' perception in learning English.

According to Akobirov and Vokhidova (2018), the utilization of Telegram app in an ESL classroom gives a lot of benefit and the results are very encouraging. These findings are also supported by Naderi and Akrami (2018). They affirmed that using the Telegram app can help students improve their reading comprehension skills.

Furthermore, Setiawan and Wahyuni (2017) found the utilization of a recording tool in Telegram app had improved students' speaking skill in English. Xodabande (2017), who investigated the usability of the Telegram app in teaching English language pronunciation to ESL learners, supports (Setiawan \& Wahyuni, 2017) study. The results revealed that utilization of Telegram app helped students to improve their pronunciation significantly. According to the researcher, using the Telegram app to teach English is very beneficial. Similarly, Aghajani and Adloo (2018) affirmed that students who use Telegram app in cooperative writing were able to score well compared with the control group. Thus, it creates a positive attitude among students when they learn new words via Telegram app.

The Telegram app also has a positive impact in English vocabulary acquisition as well. Ghobadi and Taki (2018) stated that Telegram app had a positive impact on learning new vocabulary items among ESL students. Ghobadi and Taki (2018) findings are backed up by Heidari-shahreza and Khodarahmi (2018). The researchers found that students who used Telegram app can master the English language's word stress patterns very well.

According to Bello and Hadiza (2017), using Telegram app as a teaching tool could provide English teachers with relevant teaching materials and instructions. The researchers advised English teacher to plan ahead of time when using Telegram app, so that the teaching and learning would be efficient. On the other hand, Zarei (2015) investigated the effectiveness in utilizing Telegram app especially in providing feedback and developing writing skill in ESL classroom. The results revealed that the experimental group using the Telegram app outperformed the control group.

Ibrahim (2016) and Yinka and Queendarline (2018) examined on students' perception in utilizing Telegram app in ESL classroom. According to Yinka and Queendarline (2018), students use the Telegram app for both learning and teaching. Moreover, Ibrahim (2016) noted that using Telegram app enhances learning and teaching environment especially in creating and sharing information in quick and easy way.

Therefore, the current study sought to determine whether the utilization of Telegram app can enhance students' ESL writing skills as well as enhance students' perceptions towards ESL writing skills. The results from the current study would provide insight into mobile learning, particularly learning ESL writing skills via Telegram app. It would aid decision-makers in developing successful mobile learning adoption strategies.

\section{Methodology}

Quasi-experimental one group pre-test post-test design was employed in this study. 100 Form 5 students from a secondary school in Melaka had been selected for this study. The students are chosen from three classes as an intact group. Prior the intervention students were taught ESL writing using conventional method. 
Before the experiment, students were given the pre-test on ESL writing followed by questionnaire on their perception towards ESL writing. After that, the students from the three classes were taught ESL essay writing via Telegram app for four weeks by the same teacher. Since the number of students in each class was small (30 - 35 students), a group message had be sent from the teacher's personal mobile phone. Teaching and learning processes using Telegram app had been carried out twice every week (one hour for each session). After the fourth week students were given the post-test to gauge their performance in writing. Following that the questionnaire on students' perception towards ESL writing was administered. The pre-test and the posttest were also posted via Telegram app to students. The study's quantitative data was collected via pre- and post-tests and analyzed using paired sample t-test, while the data from the questionnaire was analyzed using descriptive statistics.

The questionnaires on students' perceptions of the utilization of Telegram app in learning ESL writing skills consisted of seven items and were adapted from Shazali, Shamsudin, and Yunus (2019). Strongly Disagree=1, Disagree=2, Agree=3, and Strongly Agree=4 were the four Likert scales used in the survey. The items were created in Google Form and had been posted on the Telegram app and the students were alerted via their mobile phones to respond.

During the intervention, most students found it is easy to write their essays using Telegram app. Their essays were later being copied and pasted into Word document and were corrected and graded by their teacher using Sijil Pelajaran Malaysia (Malaysian Certificate of Education) grading system. Four writing tasks given to students (one task every week). During the tasks, participants were also allowed to give constructive comments or responses to their friends' posts. This was done to create a conducive learning environment, as they probably felt more comfortable when being responded to by their classmates. Throughout the four assigned Telegram tasks, participants were allowed to ask their teacher for any clarification on the tasks given.

\section{Results and Discussion}

RQ1. Is there a significant difference between the pre-test and the post-test (after using the Telegram app) in terms of students' ESL writing skills?

\begin{tabular}{|c|c|c|c|c|c|c|c|}
\hline Test & $\mathbf{N}$ & Mean & Std. Deviation & Mean Difference & t-value & df & p-value \\
\hline Pre & 100 & 22.1 & 22.6 & & & & \\
\hline Post & 100 & 33.1 & 2.26 & $2.2 / 1$ & 4.403 & 198 & 0.000 \\
\hline
\end{tabular}

Table 1 indicated that the students' overall mean score for ESL writing skills in the post test (mean $=33.1$, $\mathrm{SD}=2.26)$ is higher than their scores in the pre-test (mean $=22.1, \mathrm{SD}=22.6)$. Findings from the paired sample t-test showed that the utilization of Telegram app significantly enhanced students in ESL writing skills in the post-test (Mean difference $=2.271, \mathrm{t}=4.403, \mathrm{df}=198, \mathrm{p}=.000$ ). Therefore, these findings answered the Research Question 1. These findings are in line with those of Ally et al. (2007) and Aghajani and Adloo (2018) which stressed mobile learning has improved their results in language learning.

The findings support the findings of Lin and $\mathrm{Yu}$ (2017), who affirmed that learning through mobile phones are more effective than traditional teaching and learning methods. In addition, the findings are parallel with those of Jamaldeen et al. (2018), who found that students used mobile learning to improve their language skills. Besides, the findings are consistent with Celik and Yaviz (2017) findings, which demonstrated that students who used mobile learning in vocabulary retention performed well.

Results of this study indicated that students performed significantly well in the post-test compared with their results in the pre-test. This is due to numerous reinforcements of new vocabulary via Telegram app. The students were aware of how to use the words correctly. Furthermore, students were motivated and attempted to go above and beyond. In addition, the teacher assisted the students in their writing skills. The findings clearly showed that the utilization of Telegram app via mobile helped the students to improve their ESL writing skills.

Studies

Volume 4, Issue 1, pp. 10-16

2021

Nair

Email:ssubadrah.nair@city.edu.my Funding: This study received no specific

Article History

Received: I July 2021

Revised: 3 August 2021

Accepted: 23 August 202

(C) 2021 by the authors; licensee Academic Publishing Group 
RQ2. Is there significant difference in students' perceptions towards ESL writing before the utilization of Telegram app compared with their perception after the utilization of Telegram app?

\begin{tabular}{cccccccc}
\multicolumn{8}{c}{ Table-2. Students' perception towards ESL writing before and after the utilization of Telegram app. } \\
\begin{tabular}{cccccccc}
\hline Test & N & Mean & Std. Deviation & Mean Difference & t-value & df & p-value \\
\hline Pre & 100 & 4.13 & 1.29 & 0.150 & 7.122 & 198 & \multirow{2}{*}{0.000} \\
Post & 100 & 5.20 & 0.77 & & & & \\
\hline
\end{tabular} Note: Level of significance is at $\mathrm{p}<0.05$.
\end{tabular}

Table 2 indicated that the mean score of students' perception towards ESL writing after the utilization of Telegram App which is higher (mean $=5.20, \mathrm{SD}=0.77$ ) than their mean before the intervention $($ mean $=$ 4.13, SD =1.29). Findings from the paired sample t-test showed that the utilization of Telegram App significantly enhanced students' perception towards ESL writing (Mean difference $=0.150, \mathrm{t}=7.122, \mathrm{df}=198$, $\mathrm{p}=.000$ ). Therefore, the findings answered the Research Question 2. These findings support findings by Naderi and Akrami (2018) which stressed the positive effect of learning instruction using Telegram app. These findings support findings by Hao et al. (2019) which concluded that students enjoyed and motivated in learning when using mobile phones.

The results of this study clearly convinced that Telegram app is effective in learning English writing. Students showed positive perceptions towards learning English writing because their friends provided support and they were not stressed while doing their writing task. Similarly, students asserted that they were motivated to write in English as they received encouraging feedback from friends in relation to corrections and constructive ideas. The motivation helped them to improve in spellings and vocabulary while writing English essays. In addition, the use of Telegram app encourages collaborative learning and creates a fun learning environment for students. This is in line with Aghajani and Adloo (2018) findings, which stressed that the Telegram app significantly helped students in improving their writing and developing their word choice in their writing task. In addition, study by the Zarei (2015) also demonstrated the effectiveness of incorporating the Telegram app into ESL classrooms, particularly for writing tasks that students find tedious.

RQ3. What are the students' perception on using the Telegram app to improve ESL writing skills?

Table-3. Students' perceptions on using the Telegram app to improve ESL writing skills.

\begin{tabular}{|c|c|c|c|c|}
\hline Items on Students' Perceptions & $\begin{array}{l}\text { Strongly } \\
\text { Disagree }\end{array}$ & Disagree & Agree & $\begin{array}{l}\text { Strongly } \\
\text { Agree }\end{array}$ \\
\hline $\begin{array}{l}\text { 1. It is easy to use Telegram app to learn writing in } \\
\text { English. }\end{array}$ & $6 \%$ & $6 \%$ & $23 \%$ & $65 \%$ \\
\hline 2. It is interesting to use Telegram app for writing task. & $2 \%$ & $2 \%$ & $33 \%$ & $63 \%$ \\
\hline Telegram app has helped me to improve writing skill. & $6 \%$ & $6 \%$ & $44 \%$ & $44 \%$ \\
\hline $\begin{array}{l}\text { 4. Using the Telegram app motivates me to learn English } \\
\text { writing. }\end{array}$ & $4 \%$ & $4 \%$ & $46 \%$ & $46 \%$ \\
\hline $\begin{array}{l}\text { 5. Reading my classmates' comments on my writing } \\
\text { helps me learn new vocabulary. }\end{array}$ & $10 \%$ & $10 \%$ & $40 \%$ & $40 \%$ \\
\hline $\begin{array}{l}\text { 6. My classmates' suggestions or comments aided me in } \\
\text { forming a good idea. }\end{array}$ & $6 \%$ & $6 \%$ & $44 \%$ & $44 \%$ \\
\hline $\begin{array}{l}\text { 7. When using the Telegram app, I will continue to write } \\
\text { in English. }\end{array}$ & $4 \%$ & $4 \%$ & $46 \%$ & $46 \%$ \\
\hline
\end{tabular}

International Journal of Educational Studies

Volume 4, Issue 1, pp. 10-16

2021

DOI: $10.53935 / 2641-533 x . v 4 i 1.55$

Corresponding Author: Subadrah Madhawa

Nair

Email:subadrah.nair@city.edu.my

Funding: This study received no specific

financial support.

Article History:

Received: 1 July 202

Revised: 3 August 2021

Accepted: 23 August 2021

(C) 2021 by the authors; licensee Academic Publishing Group
Based on the results in Table 3 the following analyses are made. These findings indicate that $88 \%$ of the students strongly agreed or agreed that it is easy to use Telegram app in learning English writing, 99\% of them found it is interesting to use Telegram app for writing task, and $88 \%$ agreed that Telegram app has helped them to improve writing skill. Followed by $92 \%$ of the students strongly agreed or agreed that they feel motivated to learn writing in English when using Telegram app. 80\% of them opined that they learn new vocabulary by reading comments of their classmates on their writing and $88 \%$ of them strongly agreed or agreed that the ideas or comments from classmates helped them to get better idea in writing. For the last item, 


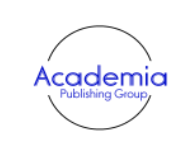

International Journal of Educational Studies

Volume 4, Issue 1, pp. 10-16

2021

DOI: $10.53935 / 2641-533 x . v 4 i 1.55$

"Corresponding Author: Subadrah Madhawa

Nair

Email: subadrah.nair@city.edu.my

Funding: This study received no specific

financial support.

financial support:

Article History:

Received: 1 July 2021

Revised: 3 August 2021

Accepted: 23 August 2021

Published: 9 September 2021

(C) 2021 by the authors; licensee Academic Publishing Group
92\% of the students strongly agreed or agreed to continue writing in English using Telegram app. This shows that Telegram app has helped to enhance students' ESL writing skills.

Current results, is also consistent with Ibrahim (2016) which revealed that the Telegram app is a simple learning tool for sharing information and teaching and learning processes. They also mentioned that the Telegram app is a helpful tool for students who are learning a new language. As a result, the findings clearly demonstrated that students' perceptions of using the Telegram app on their mobile devices aided them in improving their ESL writing skills.

\section{Conclusion}

Findings from the paired sample t-test clearly indicated that the utilization of Telegram app significantly enhanced students in ESL writing skills in the post-test. In addition, students' perception towards ESL writing also enhanced significantly after the utilization of Telegram app. In conclusion, from the perception of 100 students that participated in the Telegram tasks in this study, it is clear that Telegram app does help in developing students' writing ability in terms of new vocabulary and it boosts their motivation in learning. Even though the impact of using it is not immediate, but somehow it slowly works in a way which teachers should take into account that Telegram app can be considered as one of the pedagogical tools in teaching writing. Moreover, the writing of captions helps to widen the vocabulary range among students. Students are able to use different words to convey their thoughts, feeling and even motivate others to write well. Besides, students can learn to use the correct grammatical English structure in their writing. The students learn on how to use the correct vocabulary in sentences by reading their friends' post. In conclusion, Telegram app can be an effective pedagogical tool in teaching ESL writing.

\section{References}

Abbasi, M., \& Hashemi, M. (2013). The impacts of using mobile phone on English language vocabulary retention. International Research Journal of Applied and Basic Sciences, 4(3), 541-547.

Adams, D., Sumintono, B., Mohamed, A., \& Mohamad Noor, N. S. (2018). E-learning readiness among students of diverse backgrounds in a leading Malaysian higher education institution. Malaysian Journal of Learning and Instruction (MJLI), 15(2), 227-256. Available at: https://doi.org/10.32890/mjli2018.15.2.9.

Aghajani, M., \& Adloo, M. (2018). The effect of online cooperative learning on students' writing skills and attitudes through telegram application. International Journal of Instruction, 11(3), 433-448. Available at: https://doi.org/10.12973/iji.2018.11330a.

Akobirov, F., \& Vokhidova, N. (2018). A new generation of English learners-Telegram app users. In NELTA ELT Forum, 154.

Ally, M., McGreal, R., Schafer, S., Tin, T., \& Cheung, B. (2007). Use of mobile learning technology to train ESL adults. Paper presented at the Proceedings of the Sixth International Conference on Mobile Learning, Melbourne.

Andujar, A. (2016). Benefits of mobile instant messaging to develop ESL writing. System, 62, 63-76. Available at: https://doi.org/10.1016/j.system.2016.07.004.

Awada, G. (2016). Effect of WhatsApp on critique writing proficiency and perceptions toward learning. Cogent Education, 3(1), 1264173. Available at: https://doi.org/10.1080/2331186x.2016.1264173.

Bello, M. L., \& Hadiza, B. D. (2017). Revitalizing education through: Integrating telegram as corrective feedback in language teaching muhammad ladan bello and bello dange hadiza. SER, 17(2), 99-104. Available at: https://doi.org/10.35386/ser.v17i1.21.

Celik, O., \& Yaviz, F. (2017). The effect of using mobile applications on literal and contextual vocabulary instruction. International Journal of Learning, 10(2), 126-136.

Darmi, R., \& Albion, P. (2014). A Review of integrating mobile phone for language learning. Paper presented at the Paper Presented at the 10th International Conference Mobile Learning.

Ghobadi, S., \& Taki, S. (2018). Effects of telegram stickers on english vocabulary learning: Focus on Iranian EFL learners. Research in English Language Pedagogy, 6(1), 139- 158.

Hao, Y., Lee, K. S., Chen, S. T., \& Sim, S. C. (2019). An evaluative study of a mobile application for middle school students struggling with English vocabulary learning. Computers in Human Behavior, 95, 208-216. Available at: https://doi.org/10.1016/j.chb.2018.10.013.

Heidari-shahreza, M. A., \& Khodarahmi, Z. (2018). Effect of MALL on the acquisition of word stress patterns of English by Iranian EFL learners: The case of Telegram. Journal of Applied Linguistics and Language Research, 5(1), 40-55.

Hwang, G. J., Hsu, T. C., \& Hsieh, Y. H. (2019). Impacts of different smartphone caption/subtitle mechanisms on English listening performance and perceptions of students with different learning styles. International Journal 

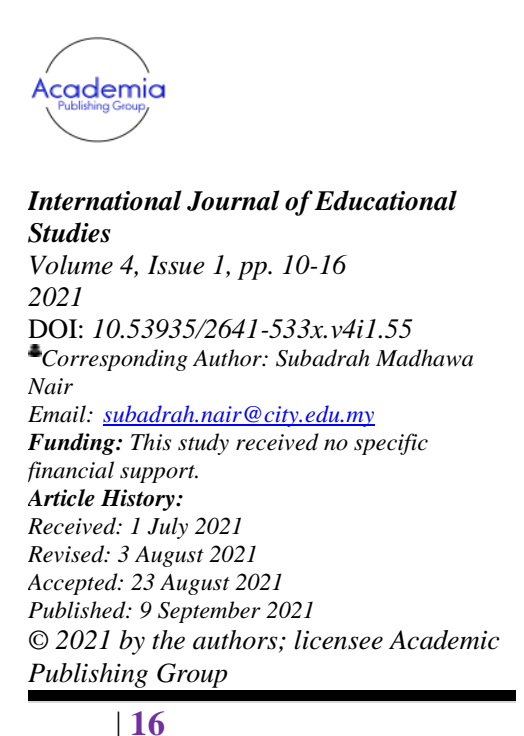

of Human-Computer Interaction, 35(4-5), 333-344. Available at: https://doi.org/10.1080/10447318.2018.1543091.

Ibrahim, M. N. (2016). Preliminary perception of teaching and learning using telegram social media tool. Esteem Academic Journal: Social Sciences \& Technology, 12(2), 95-103.

Jamaldeen, F. F., Hewagamage, K. P., \& Ekanayaka, Y. (2018). Design guidelines for creating mobile language learning applications. International Journal of Interactive Mobile Technologies, 12(3), 52-74. Available at: https://doi.org/10.3991/ijim.v12i3.8153.

Jin, N., \& Yan, Z. (2018). The construction and application of a personalized teaching space in mobile English. International Journal of Emerging Technologies in Learning, 13(11), 184-195. Available at: https://doi.org/10.3991/ijet.v13i11.9610.

Khabsarian-Dehkordi, F., \& Ameri-Golestan, A. (2016). Effects of mobile learning on acquisition and retention of vocabulary among Persian-speaking EFL learners. CALL_EJ, 17(2), 43-56.

Klímová, B., \& Pražák, P. (2019). Mobile blended learning and evaluation of its effectiveness on students' learning achievement. Paper presented at the In International Conference on Blended Learning, Springer, Cham.

Kuimova, M., Burleigh, D., Uzunboylu, H., \& Bazhenov, R. (2018). Positive effects of mobile learning on foreign language learning. TEM Journal, 7(4), 837-841.

Leis, A., Tohei, A., \& Cooke, S. D. (2015). Smartphone assisted language learning and autonomy. International Journal of Computer-Assisted Language Learning, 5(3), 75-88. Available at: https://doi.org/10.4018/ijcallt.2015070105.

Lin, C. C., \& Yu, Y. C. (2017). Effects of presentation modes on mobile-assisted vocabulary learning and cognitive load. Interactive Learning Environments, 25(4), 528-542. Available at: https://doi.org/10.1080/10494820.2016.1155160.

Naderi, N., \& Akrami, A. (2018). EFL learners' reading comprehension development through MALL: Telegram groups in focus. International Journal of Instruction, 11(2), 339-350. Available at: https://doi.org/10.12973/iji.2018.11223a.

Nadikattu, R. R. (2020). Information technologies: Rebooting the world activities during COVID-19. Retrieved from: https://ssrn.com/abstract=3622733 or http://dx.doi.org/10.2139/ssrn.3622733.

Setiawan, R., \& Wahyuni, N. C. (2017). English talk class based Telegram (E-talk castel) an innovative and creative strategy to stimulate students' speaking skill. Paper presented at the In English Language and Literature International Conference (ELLiC) Proceedings.

Shazali, S. S., Shamsudin, Z. H., \& Yunus, M. M. (2019). Instagram: A platform to develop student's writing ability. International Journal of Academic Research in Business and Social Sciences, 9(1), 88-98. Available at: https://doi.org/10.6007/ijarbss/v9-i1/5365.

Soni, V. D. (2020). Challenges and solution for artificial intelligence in cyber security of the USA. Retrieved from: https://ssrn.com/abstract=3624487 or http://dx.doi.org/10.2139/ssrn.3624487.

Xodabande, I. (2017). The effectiveness of social media network telegram in teaching English language pronunciation to Iranian EFL learners. Cogent Education, 4(1), 1-14. Available at: https://doi.org/10.1080/2331186X.2017.1347081.

Yinka, A. R., \& Queendarline, N. N. (2018). Telegram as a social media tool for teaching and learning in tertiary institutions. International Journal of Multidisciplinary Research and Development, 5(7), 95-98.

Zamakhsari, Z. (2018). Online learning: Students' participation and satisfaction. International Journal on E-Learning and Higher Eduction, 6(1), 51-69.

Zarei, N. (2015). A tellecollaborative approach to written corrective feedback. Paper presented at the International Conference ICT for Language Learning. 